\title{
Linear and Quadratic Simultaneous Demand Rate Model with Production Exponentially Increasing and Inflation
}

\author{
Vijay Singh Rajput ${ }^{1}$, Yogesh Kumar ${ }^{2}$, Amit Kumar vats ${ }^{3}$, Ranjeet Kaur ${ }^{4}$ \\ ${ }_{1,2}$ (OPJS University department of mathematics, Churu, Rajasthan) \\ ${ }^{3,4}$ (ABES Institute of Technology Ghaziabad,U.P.)
}

\begin{abstract}
In existing literature the inventory models are developed under supply chain model of a volume agile manufacturing process for the deteriorating items. In this study, a model for the producer by assuming production to be stock dependent and exponentially increasing and demand rate to be linear and quadratic simultaneously with constant deterioration rate and holding cost is developed. Shortages are not allowed. This whole study is studied in the inflationary environment. The mathematical expression for the total cost is derived and it is minimized. A numerical example has been illustrated using MATLAB to describe the model.
\end{abstract}

Keywords: Constant deterioration; production exponentially increasing, linear and quadratic Simultaneous demand rate; Inflation; Inventory; holding cost

\section{Introduction}

Stock dependent demand plays an important role in the inventory models. However, in previous years, inventory models with stock dependent demand had received little attention from researchers. It is observed that the demand rate is usually influenced by the amount in the stock. Gupta and Vrat (1986) had assumed demand rate to be a function of the initial stock. Mondal and Phaujder (1989) considered demand rate to be linear and non- linear functions of inventory in stock. Datta, T.K. et al (1991) Effects of inflation and time value of money on an inventory model with linear time dependent demand rate and shortages. Chang, J.H. et al (2010) developed partial backlogging inventory model for non-instantaneous deteriorating items with stock dependent consumption rate under inflation. Padmanabhan, G. et al (1990) developed an EOQ model for items with stock dependent consumption rate and exponential decay. Hong, J.D. et al (1990) considered the production policy for linearly increasing demand and finite uniform production rate. Khouja, M. et al (1994) had assumed an economic production lot size model with variable production rate and imperfect quality Khouja, M. (1995) considered the economic production lot size model under volume flexibility. Khouja, M. (1997) developed the scheduling of economic lot size on volume flexibility production system .Khouja, M. et al (2005) worked on production model for a flexible production system and products with short selling season. Mandal, B.N. et al (1989) worked on model for deteriorating items and stock-dependent consumption rate. Misra, R.B. (1975) developed optimum production lot size model for a system with deteriorating inventory. Sana, S. et al (2003) considered a volume flexible stock dependent inventory model. Sana, S. et al (2004) revised the volume flexible production policy for a deteriorating item with time dependent demand and shortage Sana, S.S. (2007) worked volume flexible inventory model for items with an imperfect production system. Singh, S.R. et al (2010) considered supply chain models with imperfect production process and volume flexibility under inflation. Singh, S.R. (2011) worked on deterministic two warehouse inventory model for deteriorating items with stock dependent demand and shortages under the conditions of permissible delay. Singh, S.R. (2013) developed three stage supply chain model with two warehouse, imperfect production, variable demand rate and inflation Singh, S.R. Gupta V.(2013) considered an EOQ model with volume agility, variable demand rate, weibull deterioration rate and inflation. The best production scheme depends on the swiftness of the production system. Yet there is a wide scope in the corresponding models to make it more realistic due to present business scenario. It is observed that the prices of everything going up over the time. Inflation can be described as a decline in the real value of money, a loss of purchasing power. So it is more realistic to consider the inflation in our model. In this paper deterioration rate and holding cost is constant and production rate is exponentially increasing and stock dependent. In this article, an attempt has been made to develop an EOQ model in which demand rate is considered linear and quadratic simultaneously to make it more realistic. The rest of this paper is organized as follows. Section II describes the assumptions used throughout this paper. In section III notations used in paper are listed. The mathematical formulation is given in section IV. Section V describes the mathematical solution of the problem formulated in section IV. The algorithm of the solution is provided in section VI. Concluding remarks and suggestions for future research are provided in Section VII while a numerical solution is mentioned in section VIII. 


\section{Assumptions}

The following assumptions are made in developing the model.

$>$ The inventory system is considered for two different items.

$>$ Production is exponentially increasing.

$>$ The demand rate is linear and quadratic for simultaneous equations of time dependent.

$>$ The deterioration rate is constant.

$>$ The inventory system is considered over a finite time horizon.

$>$ Holding cost is constant.

$>$ Lead time is zero.

$>$ Shortages are not allowed.

III. Notations

The following notations use for inventory model.

$\begin{aligned} D(t): & \text { A demand rate in a period }[0, \mathrm{~T}] \\ P(t): & \text { Production rate in a period }[0, \mathrm{~T}] \\ \mathrm{I}_{1 \mathrm{P}}: & \text { Inventory for first item. } \\ \mathrm{I}_{2 \mathrm{P}}: & \text { Inventory for second item. } \\ \mathrm{h}: & \text { The planning horizon. } \\ \mathrm{T}: & \text { The replenishment cycle } \\ Q_{0}: & \text { Initial ordering quantity } \\ \mathrm{N}: & \text { The replenishment number in the planning horizon } \mathrm{H} \\ \mathrm{C}_{1 \mathrm{P}}: & \text { The ordering cost per order } \\ \mathrm{C}_{2 \mathrm{P}}: & \text { The purchasing cost per unit } \\ \mathrm{C}_{3 \mathrm{P}}: & \text { The holding cost per unit per unit time } \\ P C_{P}: & \text { Purchasing cost in a cycle period }[0, \mathrm{~T}] \\ O C_{P}: & \text { Ordering cost } \\ H C_{P}: & \text { Holding cost } \\ \mathrm{T}^{*}: & \text { Optimal length size } \\ Q_{0}^{*}: & \text { Optimal initial order quantity } \\ (T, N): & \text { Total inventory cost }\end{aligned}$

\section{Mathematical Formulation}

Consider the inventory model of dependent production exponentially increasing and demand rate linear and quadratic for simultaneous equation respectively with constant deterioration. As the inventory reduces due to demand rate as well as deterioration rate during the interval, the differential representing the inventory status is governed by $[0, \mathrm{~T}]$

$$
\frac{d I(t)}{d t}+\theta I(t)=P(t)-D(t), 0 \leq t \leq T
$$

\section{Mathematical Solution}

The solution with boundary condition $I(T)=0$ of the Equation lie interval $0 \leq t \leq t_{P}$

$$
\begin{aligned}
& \frac{d I_{1 P}(t)}{d t}+\theta I_{1 P}(t)=e^{\alpha t}-(a+b t), 0 \leq t \leq t_{P} \\
& I_{1 P}(t)=\frac{1}{\alpha+\theta}\left(e^{\alpha t}-e^{\theta t}\right)-\left(1-e^{-\theta t}\right)\left(\frac{a}{\theta}-\frac{b}{\theta^{2}}\right)-\frac{b t}{\theta}
\end{aligned}
$$

And for another item in the interval $t_{P} \leq t \leq T$

$$
\frac{d I_{2 P}(t)}{d t}+\theta I_{2 P}(t)=e^{\alpha t}-\left(a+b t+c t^{2}\right), t_{P} \leq t \leq T
$$




$$
\begin{aligned}
& I_{2 P}(t)=\frac{1}{\theta}\left[\left(a-b+\frac{c}{\theta^{2}}\right)+\left(b-\frac{2 c}{\theta}\right) T+c T^{2}\right] e^{\theta(T-t)}-\frac{e^{\alpha T}}{\alpha+\theta} e^{\theta(T-t)} \\
& -\frac{1}{\theta}\left[\left(a-b+\frac{c}{\theta^{2}}\right)+\left(b-\frac{2 c}{\theta}\right) t+c t^{2}\right]+\frac{e^{\alpha T}}{\alpha+\theta}
\end{aligned}
$$

So the initial order quantity is obtained by putting the boundary condition in Equation (5) $I_{2 P}(0)=Q_{0}$. Therefore,

$$
\begin{aligned}
& Q_{0}=\frac{1}{\theta}\left[\left(a-b+\frac{c}{\theta^{2}}\right)+\left(b-\frac{2 c}{\theta}\right) T+c T^{2}\right] e^{\theta T}-\frac{e^{(\alpha+\theta) T}}{\alpha+\theta} \\
& -\frac{1}{\theta}\left(a-b+\frac{c}{\theta^{2}}\right)+\frac{e^{\alpha T}}{\alpha+\theta}
\end{aligned}
$$

\subsection{Ordering Cost}

$$
\begin{gathered}
O C_{P}=C_{1 P} \sum_{i=0}^{N} e^{-r_{i} T} \\
=C_{1 P} \frac{e^{\frac{r h}{N}}-e^{\frac{-r h}{N}}}{e^{\frac{r h}{N}}-1}
\end{gathered}
$$

\subsection{Purchasing Cost}

$$
\begin{aligned}
& P C_{P}=C_{2 P} \sum_{i=0}^{N-1} Q_{0} e^{-r_{i} T} \\
& =C_{2 P}\left[\begin{array}{l}
\frac{1}{\theta}\left[\left(a-b+\frac{c}{\theta^{2}}\right)+\left(b-\frac{2 c}{\theta}\right) T+c T^{2}\right] e^{\theta T}-\frac{e^{(\alpha+\theta) T}}{\alpha+\theta} \\
-\frac{1}{\theta}\left(a-b+\frac{c}{\theta^{2}}\right)+\frac{e^{\alpha T}}{\alpha+\theta}
\end{array}\right]\left(\frac{1-e^{r h}}{1-e^{\frac{r h}{N}}}\right)
\end{aligned}
$$

\subsection{Production Cost for the cycle $[0, T]$}

$$
\begin{aligned}
C P & =\sum_{i=0}^{N-1}\left[\int_{0}^{t_{P}} e^{(\alpha-r) t}\right] e^{-r_{i} T} \\
& =\left[\frac{e^{(\alpha-r) t_{P}}-1}{\alpha-r}\right]\left(\frac{1-e^{r h}}{1-e^{\frac{r h}{N}}}\right)
\end{aligned}
$$

4.4 Holding Cost for the cycle [0, T]

$$
H C=\sum_{i=0}^{N-1} C_{3 P}\left[\int_{0}^{t_{P}} I_{1 P}(t) e^{-r t} d t+\int_{t_{P}}^{T} I_{2 P}(t) e^{-r t} d t\right] e^{-r_{i} T}
$$




$$
\begin{aligned}
& =\sum_{i=0}^{N-1} C_{3 P}\left[\begin{array}{l}
\int_{0}^{t_{p}}\left(\frac{1}{\alpha+\theta}\left(e^{\alpha t}-e^{\theta t}\right)-\left(1-e^{-\theta t}\right)\left(\frac{a}{\theta}-\frac{b}{\theta^{2}}\right)-\frac{b t}{\theta}\right) e^{-r t} d t \\
+\int_{t_{P}}^{T} I_{2 P}\left(\begin{array}{l}
\frac{1}{\theta}\left[\left(a-b+\frac{c}{\theta^{2}}\right)+\left(b-\frac{2 c}{\theta}\right) T+c T^{2}\right] e^{\theta(T-t)}-\frac{e^{\alpha T}}{\alpha+\theta} e^{\theta(T-t)} \\
-\frac{1}{\theta}\left[\left(a-b+\frac{c}{\theta^{2}}\right)+\left(b-\frac{2 r}{\theta}\right) t+c t^{2}\right]+\frac{e^{\alpha T}}{\alpha+\theta}
\end{array}\right] e^{-r t} d t
\end{array}\right] e^{-r_{i} T} \\
& =C_{3 P}\left[\begin{array}{l}
\int_{0}^{t_{P}}\left(\frac{1}{\alpha+\theta}\left(e^{\alpha t}-e^{\theta t}\right)-\left(1-e^{-\theta t}\right)\left(\frac{a}{\theta}-\frac{b}{\theta^{2}}\right)-\frac{b t}{\theta}\right) e^{-r t} d t \\
+\int_{t_{P}}^{T}\left(\begin{array}{l}
\frac{1}{\theta}\left[\left(a-b+\frac{c}{\theta^{2}}\right)+\left(b-\frac{2 c}{\theta}\right) T+c T^{2}\right] e^{\theta(T-t)}-\frac{e^{\alpha T}}{\alpha+\theta} e^{\theta(T-t)} \\
-\frac{1}{\theta}\left[\left(a-b+\frac{c}{\theta^{2}}\right)+\left(b-\frac{2 c}{\theta}\right) t+c t^{2}\right]+\frac{e^{\alpha T}}{\alpha+\theta}
\end{array}\right] e^{-r t} d t
\end{array}\right]\left(\begin{array}{l}
1-e^{r h} \\
1-e^{\frac{r h}{N}}
\end{array}\right) \\
& =C_{3 P}\left[\begin{array}{l}
\frac{1}{\alpha+\theta}\left(\frac{e^{(\alpha-r) t_{P}}-1}{(\alpha-r)}-\frac{e^{(\theta-r) t_{P}}-1}{(\theta-r)}\right)+\left(\frac{a}{\theta}-\frac{b}{\theta^{2}}\right)\left(\frac{e^{-r t_{P}}-1}{r}-\frac{e^{-(\theta+r) t_{P}}-1}{(\theta+r)}\right) \\
+\frac{b t_{P}}{r \theta} e^{-r t_{P}}+\frac{b t}{r^{2} \theta} e^{-r t_{P}}-\frac{b}{r^{2} \theta} \\
+\frac{1}{\theta}\left[\left(a-b+\frac{c}{\theta^{2}}\right)+\left(b-\frac{2 c}{\theta}\right) T+c T^{2}\right]\left(\frac{e^{-r T}-e^{\theta T-(\theta+r) t_{P}}}{(\theta+r)}-\frac{e^{(\alpha-r) T}-e^{(\alpha+\theta) T-(\theta+r) t_{P}}}{(\alpha+\theta)(\theta+r)}\right) \\
+\frac{1}{r \theta}\left(a-b+\frac{c}{\theta^{2}}\right)\left(e^{-r T}-e^{-r t_{P}}\right)-\frac{1}{r}\left(b-\frac{2 c}{\theta}\right)\left(T e^{-r T}-t_{P} e^{-r t_{P}}\right) \\
-\frac{1}{r^{2}}\left(b-\frac{2 c}{\theta}\right)\left(e^{-r T}-e^{-r t_{P}}\right) \\
-\left(\frac{c T^{2}}{r}+\frac{2 c T}{r^{2}}+\frac{2 c}{r^{3}}\right) e^{-r T}+\left(\frac{c t_{P}^{2}}{r}+\frac{2 c t_{P}}{r^{2}}+\frac{2 c}{r^{3}}\right) e^{-r t_{P}}-\frac{e^{(\alpha-r) T}-e^{\left(\alpha T-r t_{P}\right)}}{r(\alpha+\theta)}
\end{array}\right]\left(\begin{array}{l}
\frac{r h}{r h} \\
1-e^{\frac{r h}{N}}
\end{array}\right)
\end{aligned}
$$

4.6 Total inventory cost $T C(T, N)=$ Ordering cost $\left(\mathrm{OC}_{\mathrm{P}}\right)+$ Purchasing Cost $\left(\mathrm{PC}_{\mathrm{P}}\right)$

$$
+ \text { Cost of Production }\left(\mathrm{CP}_{\mathrm{P}}\right)+\text { Holding cost }\left(\mathrm{HC}_{\mathrm{P}}\right)
$$

Therefore the total variable cost per unit time is 


$$
\left.\begin{array}{l}
T C(T, N)=C_{1 P}\left[\frac{e^{\frac{r h}{N}}-e^{\frac{-r h}{N}}}{e^{\frac{r h}{N}}-1}\right] \\
+\left\{\begin{array}{l}
C_{2 P}\left[\begin{array}{l}
\left.\frac{1}{\theta}\left[\left(a-b+\frac{c}{\theta^{2}}\right)+\left(b-\frac{2 c}{\theta}\right) T+c T^{2}\right] e^{\theta T}-\frac{e^{(\alpha+\theta) T}}{\alpha+\theta}\right]+\left[\frac{e^{(\alpha-r) t_{P}}-1}{\alpha-r}\right] \\
-\frac{1}{\theta}\left(a-b+\frac{c}{\theta^{2}}\right)+\frac{e^{\alpha T}}{\alpha+\theta}
\end{array}\right] \\
{\left[\begin{array}{l}
\frac{1}{\alpha+\theta}\left(\frac{e^{(\alpha-r) t_{P}}-1}{(\alpha-r)}-\frac{e^{(\theta-r) t_{P}}-1}{(\theta-r)}\right)+\left(\frac{a}{\theta}-\frac{b}{\theta^{2}}\right)\left(\frac{e^{-r t_{P}}-1}{r}-\frac{e^{-(\theta+r) t_{P}}-1}{(\theta+r)}\right) \\
+\frac{b t_{P}}{r \theta} e^{-r t_{P}}+\frac{b t}{r^{2} \theta} e^{-r t_{P}}-\frac{b}{r^{2} \theta} \\
+\frac{1}{\theta}\left[\begin{array}{l}
\left(a-b+\frac{c}{\theta^{2}}\right) \\
+\left(b-\frac{2 c}{\theta}\right) T+c T^{2}
\end{array}\right]\left(\frac{e^{-r T}-e^{\theta T-(\theta+r) t_{P}}}{(\theta+r)}-\frac{e^{(\alpha-r) T}-e^{(\alpha+\theta) T-(\theta+r) t_{P}}}{(\alpha+\theta)(\theta+r)}\right) \\
+\frac{1}{r \theta}\left(a-b+\frac{c}{\theta^{2}}\right)\left(e^{-r T}-e^{-r t_{P}}\right)-\frac{1}{r}\left(b-\frac{2 c}{\theta}\right)\left(T e^{-r T}-t_{P} e^{-r t_{P}}\right) \\
-\frac{1}{r^{2}}\left(b-\frac{2 c}{\theta}\right)\left(e^{-r T}-e^{-r t_{P}}\right)-\left(\frac{c T^{2}}{r}+\frac{2 c T}{r^{2}}+\frac{2 c}{r^{3}}\right) e^{-r T} \\
+\left(\frac{c t_{P}^{2}}{r}+\frac{2 c t_{P}}{r^{2}}+\frac{2 c}{r^{3}}\right) e^{-r t_{P}}-\frac{e^{(\alpha-r) T}-e^{\left(\alpha T-r t_{P}\right)}}{r(\alpha+\theta)}
\end{array}\right]}
\end{array}\right)
\end{array} \mid \begin{array}{l}
1-e^{r h} \\
1-e^{\frac{r h}{N}}
\end{array}\right)
$$

The necessary and sufficient conditions for minimizing the total cost where $\mathrm{TC}$ is a function of $\mathrm{T}$ and $\mathrm{N}$, put $\frac{d T C(T, N)}{d T}=0$ And $\frac{d^{2} T C(T, N)}{d T^{2}}>0$, we get the optimal value of TC and cycle of production $\mathrm{N}$.

\section{Algorithm}

To find the solution following algorithm is used

Step1: Find derivative $\frac{d T C(T, N)}{d T}$ and put $\frac{d T C(T, N)}{d T}=0$

Step2: Solve equation for $\mathrm{T}$

Step3: Find the derivative $\frac{d^{2} T C(T, N)}{d T^{2}}$ and check $\frac{d^{2} T C(T, N)}{d T^{2}}>0$ for $\mathrm{T}^{*}$ optimal length Step4: Find optimal total cost $\mathrm{TC}^{*}\left(\mathrm{~T}^{*}, \mathrm{~N}\right)$ and initial order quantity $\mathrm{Q}^{*}\left(\mathrm{~T}^{*}, \mathrm{~N}\right)$

\section{Conclusion}

In the present paper, we developed an inventory model for constant deteriorating item with inflation, exponentially increasing production and demand rate are linear and quadratic for simultaneous equation respectively and without shortages give analytical solution, numerical solution and that minimize the total inventory cost. The holding cost is constant function with inflation. This model can further be extended by taking more realistic assumptions such as finite replenishment rate, probabilistic demand rate and also can take the production rate is different for different items etc.

\section{Numerical Solution}

Consider an inventory system with the following parameter in proper units $a=5, b=7, c=3, \alpha=0.8, \theta=0.2, C_{1 P}=R s .200 /$ order $\quad C_{2 P}=R s .2 /$ unit,$C_{3 P}=R s .6 /$ unit $/$ month,$r=0.02$ 
and $h=36$ months. The Computer output of the program by using Mat lab software is $N^{*}=12.03, Q_{0}^{*}=156.89$ and $\mathrm{TC}^{*}=$ Rs.29758.81. As the production rate is exponentially increasing, if the value of $\alpha$ decreases then Total Cost TC also decreases and the item having linear demand rate corresponds to increase in Total Cost.

\section{References}

[1]. Chang, J.H. and Lin, F.W. 2010 "A partial backlogging inventory model for non-instantaneous deteriorating items with stock dependent consumption rate under inflation" Yugoslav Journal of Operation Research, 20(1), 35-54.

[2]. Datta, T.K. and Pal, A.K. 1991. Effects of inflation and time value of money on an inventory model with linear time dependent demand rate and shortages. European Journal of Operation Research, 52(3), 326-333.

[3]. Padmanabhan, G. and Vrat, P. 1990. An EOQ model for items with stock dependent consumption rate and exponential decay. Engineering Costs and Production Economics, 18(3), 241-246.

[4]. Hong, J.D., Sandrapaty, R.R. and Hayya, J.C. 1990 "A production policy for linearly increasing demand and finite uniform production rate Computers Industrial Engg., 18(2), 119-127.

[5]. Khouja, M. and Mehrez, A. 1994. "An economic production lot size model with variable production rate and imperfect quality" Journal of operational Research Society, 45(12), 1405-1417.

[6]. Khouja, M. 1995. The economic production lot size model under volume flexibility. Computers and operations Research, 22(5), 515-523.

[7]. Khouja, M. 1997. "The scheduling of economic lot size on volume flexibility production system" International Journal of Production Economics, 48(1), 73-86.

[8]. Khouja, M. and Mehrez, A. 2005. "A production model for a flexible production system and products with short selling season" Journal of Applied Mathematics and Decision Sciences, 2005(4), 213-223.

[9]. Moon, I., Gallego, G. and Simchi-Levi, D. 1991. "Controllable production rate in a family production context" International Journal of production Research, 29(12), 2459-2470.

[10]. Mandal, B.N. and Phaujdar, S. 1989. "An Inventory model for deteriorating items and stock-dependent consumption rate" Journal of the Operations Research Society, 40(5), 483-488.

[11]. Misra, R.B. 1975. "Optimum production lot size model for a system with deteriorating inventory" International Journal of Production Research, 13(5), 459-505.

[12]. Sana, S. and Chaudhuri, K.S. 2003. "On a volume flexible stock dependent inventory model" Advance Modeling and Optimization, 5(3), 197-210.

[13]. Sana, S. and Chaudhuri, K.S. 2004. "On a volume flexible production policy for a deteriorating item with time dependent demand and shortage" Advanced Modeling and Optimization, 6(1), 57-73.

[14]. Sana, S.S., Goyal, S.K. and Chaudhuri, K.S. 2007. "On a volume flexible inventory model for items with an imperfect production system" International Journal of Operational Research, 2(1), 64-80.

[15]. Singh, S.R. and Urvashi. 2010. Supply chain models with imperfect production process and volume flexibility under inflation. IUP journal of Supply Chain Management,7(1\&2), 61-76.

[16]. Singh, S.R., Kumari, R. and Kumar, N. 2011. "A deterministic two warehouse inventory model for deteriorating items with stock dependent demand and shortages under the conditions of permissible delay" International Journal of Mathematical Modelling and Numerical Optimization, 2(4), 357-375.

[17]. Singh, S.R., Gupta, V. and Gupta, P. 2013. Three stage supply chain model with two warehouse, imperfect production, variable demand rate and inflation. International Journal of Industrial Engineering Computations, 4(1), 81-92.

[18]. Singh, S.R. Gupta V,(2013) EOQ Model with Volume Agility, Variable Demand Rate, Weibull Deterioration Rate and Inflation International Journal of Computer Applications 72(.23), $0975-8887$ 